Pacific Journal of Mathematics

RECIPROCITY AND JACOBI SUMS 


\section{RECIPROCITY AND JACOBI SUMS}

Joseph B. Muskat

Recently N. C. Ankeny derived a law of rth power reciprocity, where $r$ is an odd prime:

$q$ is an $r$ th power residue, modulo $p \equiv 1(\bmod r)$, if and only if the $r$ th power of the Gaussian sum (or Lagrange resolvent) $\tau(\chi)$, which depends upon $p$ and $r$, is an $r$ th power in $G F\left(q^{f}\right)$, where $q$ belongs to the exponent $f(\bmod r)$.

$\tau(\chi)^{r}$ can be written as the product of algebraic integers known as Jacobi sums. Conditions in which the reciprocity criterion can be expressed in terms of a single Jacobi sum are presented in this paper.

That the law of prime power reciprocity is a generalization of the law of quadratic reciprocity is suggested by the following formulation of the latter:

If $p$ and $q$ are distinct odd primes, then $q$ is a quadratic residue $(\bmod p)$ if and only if $(-1)^{(p-1) / 2} p=\tau(\psi)^{2}$ is a quadratic residue $(\bmod q)$. Here $\psi$ denotes the nonprincipal quadratic character modulo $p$ (the Legendre symbol) and

$$
\tau(\psi)=\sum_{n=1}^{p-1} \psi(n) e^{2 \pi i n / p}
$$

is a Gaussian sum.

A complete statement of Ankeny's result is the following:

Let $r$ be an odd prime. $Q\left(\zeta_{r}\right)$ will denote the cyclotomic field obtained by adjoining $\zeta_{r}=e^{2 \pi i / r}$ to the field of rationals $Q$.

Let $p$ be a prime $\equiv 1(\bmod r)$. Let $\chi$ denote a fixed primitive $r$ th power multiplicative character $(\bmod p)$. Define the Gaussian sum

$$
\tau\left(\chi^{k}\right)=\sum_{n=1}^{p-1} \chi^{k}(n) e^{2 \pi i n / p}, \quad r \nmid k .
$$

Let $q$ be a prime distinct from $r$, belonging to the exponent $f(\bmod r)$. Then

$$
\tau(\chi)^{q^{\rho}-1}=\left[\tau(\chi)^{r}\right]^{\left(q^{\rho}-1\right) / r} \equiv \chi(q)^{-\rho} \quad(\bmod q) .
$$

Consequently, if $\mathfrak{q}$ is any one of the prime ideal divisors of the ideal $(q)$ in $Q\left(\zeta_{r}\right), q$ is an $r$ th power $(\bmod p)$ if and only if $\tau(\chi)^{r}$ is an $r$ th power in $Q\left(\zeta_{r}\right) / q$, a field of $q^{f}$ elements; i.e.,

$$
\chi(q)=1 \text { if and only if } \tau(\chi)^{r} \equiv \beta^{r}(\bmod q)
$$




$$
\text { for some } \beta \in Q\left(\zeta_{r}\right)[1, \text { Th. 2] . }
$$

The following properties of the Gaussian sums are well known:

Assume $k \not \equiv 0(\bmod r)$.

$$
\begin{gathered}
\tau\left(\chi^{k}\right) \tau\left(\chi^{-k}\right)=p \\
\tau\left(\chi^{k}\right) \notin Q\left(\zeta_{r}\right), \text { but } \tau\left(\chi^{k}\right)^{t} / \tau\left(\chi^{k t}\right) \in Q\left(\zeta_{r}\right) .
\end{gathered}
$$

In particular,

$$
\tau\left(\chi^{k}\right)^{r} \in Q\left(\zeta_{r}\right)
$$

During the nineteenth century several people worked on special cases of the problem solved by Ankeny. C. G. J. Jacobi treated $r=3$ in [3]. Using Cauchy's result that

$$
\tau(\chi)^{q} / \tau\left(\chi^{q}\right) \equiv \chi(q)^{-q}(\bmod q), \quad[6, p .108]
$$

T. Pepin showed that if $q \equiv \pm 1(\bmod r)$, then $\chi(q)=1$ if and only if $\tau(\chi)^{r} / \tau\left(\chi^{2}\right)^{r}$ is an $r$ th power residue $(\bmod q)$, $([6$, pp. 117, 120]).

Define the Jacobi sums

$$
\pi\left(\chi^{a}, \chi^{b}\right)=\sum_{n=2}^{p-1} \chi^{a}(n) \chi^{b}(1-n)=\sum_{j=0}^{r-1} c_{j} \zeta_{r}^{j} .
$$

If $r$ does not divide $a, b$, or $a+b$,

$$
\pi\left(\chi^{a}, \chi^{b}\right)=\tau\left(\chi^{a}\right) \tau\left(\chi^{b}\right) / \tau\left(\chi^{a+b}\right),
$$

so by (2)

$$
\pi\left(\chi^{a}, \chi^{b}\right) \pi\left(\chi^{-a}, \chi^{-b}\right)=p
$$

(For information on Jacobi sums see [2, Ch. 20])

$\tau(\chi)^{r}$ can be expressed as a product of Jacobi sums, as follows:

$$
\tau(\chi)^{r}=\tau(\chi) \tau\left(\chi^{r-1}\right) \prod_{j=1}^{r-2} \tau(\chi) \tau\left(\chi^{j}\right) / \tau\left(\chi^{j+1}\right)=p \prod_{j=1}^{r-2} \pi\left(\chi, \chi^{j}\right), \text { by }(2) .
$$

For $r=3, \tau(\chi)^{r}=p \pi(\chi, \chi)$, so that knowing $\pi(\chi, \chi)$ gives complete information about reciprocity. For $r>3$, however, it is often necessary to consider products of Jacobi sums. Some cases where $\pi(\chi, \chi)$ itself gives complete information about reciprocity are described in the following two theorems: Then

Notation. For brevity, let $\pi[t]=\pi\left(\chi^{t}, \chi^{t}\right)$. Let $\pi[1]=\sum_{j=0}^{r-1} c_{j} \zeta_{r}^{j}$

$$
\pi[t]=\sum_{j=0}^{r-1} c_{j} \zeta_{r}^{j t}
$$


Let 2 belong to the exponent $s(\bmod r)$.

LEMMA. $\pi[t]^{h} \equiv \pi\left[t q^{h}\right](\bmod q)$.

Proof.

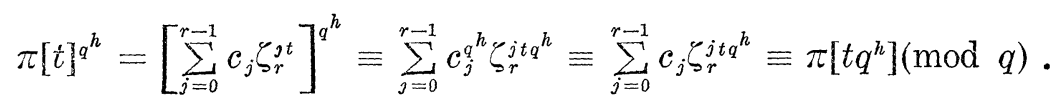

Theorem 1. Assume $2^{r-1} \not \equiv 1\left(\bmod r^{2}\right)$. If there exists an integer $u$ such that $q^{u} \equiv 2(\bmod r)$, then $\tau(\chi)^{r}$ is an $r$ th power in $Q\left(\zeta_{r}\right) / q$ if and only if $\pi(\chi, \chi)$ is.

Proof. By an identity attributed to Cauchy, [6, p. 112]

$$
\begin{aligned}
\tau(\chi)^{2^{s-1}} & =\pi[1]^{2^{s-1}} \pi[2]^{s-2} \pi[4]^{2^{s-3}} \cdots \pi\left[2^{s-2}\right]^{2} \pi\left[2^{s-1}\right] \\
& =\prod_{j=0}^{s-1} \pi\left[2^{j}\right]^{s-j-1}=\prod_{j=0}^{s-1} \pi\left[q^{u j}\right]^{2^{s-j-1}} \\
& =\beta^{r} \prod_{j=0}^{s-1} \pi\left[q^{u j}\right]^{q u(s-j-1)}, \quad \text { for some } \beta \in Q\left(\zeta_{r}\right) .
\end{aligned}
$$

To the $j$ th factor of the product in (4) apply the lemma with $t=1$ and $h=u j$ :

$$
\begin{aligned}
& \tau(\chi)^{2^{s}-1} \equiv \beta^{r} \prod_{j=0}^{s-1} \pi\left[q^{0}\right]^{q^{u(s-1)}} \equiv \beta^{r} \pi[1]^{s q^{u(s-1)}} \\
& \equiv \gamma^{r} \pi[1] 2^{s-1} s(\bmod q), \quad \text { for some } \gamma \in Q\left(\zeta_{r}\right) .
\end{aligned}
$$

Since $r^{2} \nmid 2^{r-1}-1, r \nmid\left(2^{s}-1\right) / r$. Also, $r \nmid 2^{s-1} s$. It follows that $\tau(\chi)^{r}$ is an $r$ th power in $Q\left(\zeta_{r}\right) / q$ if and only if $\pi(\chi, \chi)$ is.

EXAMPLE. $r=7, q=3 . \quad s=3, u=2$.

$$
\begin{aligned}
\tau(\chi)^{7} & =\pi[1]^{4} \pi[2]^{2} \pi[4]=\beta^{7} \pi[1]^{3^{4}} \pi\left[3^{2}\right]^{3^{2}} \pi\left[3^{4}\right]^{3^{0}} \\
& \equiv \beta^{7}\left[\pi[1]^{3^{4}}\right]^{3} \equiv \beta^{7} \pi[1]^{3^{4} \cdot 3}(\bmod 3) .
\end{aligned}
$$

(A different treatment of the example was given in $[5, p .351]$.)

THEOREM 2. Assume $2^{r-1} \neq 1\left(\bmod r^{2}\right), r>3$, and $s \equiv 2(\bmod 4)$. If there exists an integer $v$ such that $q^{v} \equiv 4(\bmod r)$, then $\tau(\chi)^{r}$ is an $r$ th power in $Q\left(\zeta_{r}\right) / q$ if and only if $\pi(\chi, \chi)$ is.

Proof.

$$
\tau(\chi)^{2^{s-1}}=\prod_{j=0}^{s / 2-1} \pi\left[2^{2 j}\right]^{2^{s-1-2 j}} \pi\left[2^{2 j+1}\right]^{2^{s-2-2 j}}
$$




$$
\begin{aligned}
& =\prod_{j=0}^{s / 2-1} \pi\left[q^{v j}\right]^{2^{s-1-2 j}} \pi\left[2 q^{v j}\right]^{2^{s-2-2 j}} \\
& =\beta^{r} \prod_{j=0}^{s / 2-1} \pi\left[q^{v j}\right]^{2 q^{v(s / 2-1-j)}} \pi\left[2 q^{v j}\right]^{q^{v(s / 2-1-j)}},
\end{aligned}
$$

for some $\beta \in Q\left(\zeta_{r}\right)$,

$$
\equiv \beta^{r}\left[\pi\left[q^{0}\right]^{2 q^{v(s / 2-1)}} \pi\left[2 q^{0}\right]^{q^{v(s / 2-1)}}\right]^{s / 2}(\bmod q),
$$

by applying the Lemma with $h=v j$ and $t=1$, then 2 , to the $j$ th factor of (5). Now apply the Lemma to the second factor of (6) with $t=2, h=v(s-2) / 4$ :

$$
\begin{aligned}
\tau(\chi)^{2 s-1} & \equiv \beta^{r}\left[\pi[1]^{2 q^{v(s / 2-1)}} \pi\left[2 q^{v(s-2) / 4}\right]^{q^{v(s-2) / 4}}\right]^{s / 2} \\
& \equiv \beta^{r}\left[\pi[1]^{2 q^{v(s / 2-1)}} \pi\left[2 \cdot 4^{(s-2) / 4}\right]^{q^{v(s-2) / 4}}\right]^{s / 2} \\
& \equiv \gamma^{r}\left[\pi[1]^{2^{s-1}} \pi\left[2^{s / 2}\right]^{s / 2-1}\right]^{s / 2},
\end{aligned}
$$

for some $\gamma \in Q\left(\zeta_{r}\right)$,

$$
\equiv \gamma^{r}\left[\pi[1]^{2^{s-1}} \pi[-1]^{2 s / 2-1}\right]^{s / 2}(\bmod q) .
$$

By (3)

$$
\tau(\chi)^{2 s-1} \equiv \gamma^{r}\left[p^{2 s / 2-1} \pi[1]^{2 s-1}-{ }^{s / 2-1}\right]^{s / 2}(\bmod q) .
$$

Since $r>3, q \neq \equiv 1(\bmod r)$, so $p$ is an $r$ th power in $Q\left(\zeta_{r}\right) / q$.

$$
\begin{aligned}
& 2^{s-1}-2^{s / 2-1} \equiv 1(\bmod r), \text { so } \\
& \tau(\chi)^{2^{s-1}} \equiv \delta^{r} \pi[1]^{s / 2}(\bmod \mathfrak{q}),
\end{aligned}
$$

for some $\delta \in Q\left(\zeta_{r}\right) . \quad r \nmid\left(2^{s}-1\right) / r, r \nmid s / 2$, and the theorem follows.

In Theorem 3 of [5] the above results were proved for the following values of $q$, under the restriction $2^{r-1} \not \equiv 1\left(\bmod r^{2}\right)$ :

(a) $q \equiv 2(\bmod r)$.

(b) $r>3, q \equiv-2(\bmod r)$.

Part (a) is included in Theorem 1. Part (b) has three cases:

If $s$ is odd, $(-2)^{s+1}=2^{s} \cdot 2 \equiv 2(\bmod r)$. Theorem 1 applies, with $u=s+1$.

If $s \equiv 2(\bmod 4),(-2)^{2}=4$. Theorem 2 applies, with $v=2$.

If $s \equiv 0(\bmod 4),(-2)^{s / 2+1}=-(2)^{s / 2}(2) \equiv 2(\bmod r)$. Theorem 1 applies, with $u=s / 2+1$.

For certain small values of $q$ and $r$ it is possible to characterize when $\chi(q)=1$ in terms of the coefficients of $\pi[1](\bmod p)$. Pepin gave the following three (the first not quite correctly).

Let $r=5 . \quad \chi(3)=1$ if and only if $c_{1} \equiv c_{*}(\bmod 3)$ and

$$
c_{2} \equiv c_{3}(\bmod 3)[6, p .132] \text {. }
$$

Let $r=7 . \quad \chi(3)=1$ if and only if $c_{1} \equiv c_{2} \equiv c_{+}(\bmod 3)$ and 


$$
c_{3} \equiv c_{5} \equiv c_{6}(\bmod 3)[6, \text { pp. 145-146] } .
$$

$\chi(2)=1$ if and only if $c_{0}$ is odd [6, p. 122] .

Analogous criteria for $r=5, q=7$ and $r=7, q=5$ can be found in $[5$, p. 349].

A more general result, which yields only a sufficient condition, however, was suggested by Emma Lehmer [4], who proved it for $r=5$.

Theorem 3: Assume $2^{r-1} \not \equiv 1\left(\bmod r^{2}\right)$, and $r>3$. Let $g$ be $a$ primitive root, modulo $r$. If $c_{g} \equiv c_{g^{3}} \equiv c_{g^{5}} \equiv \cdots \equiv c_{g^{r-2}}(\bmod q)$ and $c_{g}{ }^{2} \equiv c_{g^{4}} \equiv c_{g^{6}} \equiv \cdots \equiv c_{1}(\bmod q)$, then $q$ is an $r$ th power residue $(\bmod p)$.

$$
\begin{aligned}
& \text { Proof. Let } \lambda=\sum_{j=0}^{\frac{r-3}{2}} \zeta_{r}^{g^{2 j}}, \mu=\sum_{j=0}^{\frac{r-3}{2}} \zeta_{r}^{g^{2 j+1}} \\
& \pi[1]=\sum_{j=0}^{r-1} c_{j} \zeta_{r}^{j}=\sum_{j=1}^{r-1}\left(c_{j}-c_{0}\right) \zeta_{r}^{j} \equiv\left(c_{1}-c_{0}\right) \lambda+\left(c_{g}-c_{0}\right) \mu(\bmod q) .
\end{aligned}
$$

Similarly,

$$
\pi[g] \equiv\left(c_{1}-c_{0}\right) \mu+\left(c_{g}-c_{0}\right) \lambda(\bmod q) .
$$

If 2 is a quadratic residue, modulo $r$,

$$
\begin{aligned}
\tau(\chi)^{2^{s-1}} & =\prod_{j=0}^{s-1} \pi\left[2^{j}\right]^{2^{s-j-1}} \equiv \prod_{j=0}^{s-1}\left[\left(c_{1}-c_{0}\right) \lambda+\left(c_{g}-c_{0}\right) \mu\right]^{2 s-j-1} \\
& \equiv\left[\left(c_{1}-c_{0}\right) \lambda+\left(c_{g}-c_{0}\right) \mu\right]^{2 s-1}(\bmod q)
\end{aligned}
$$

If 2 is a quadratic nonresidue, modulo $r$,

$$
\begin{aligned}
\tau(\chi)^{2 s-1}= & \prod_{j=0}^{s / 2-1} \pi\left[2^{2 j}\right]^{s^{s-1-2 j}} \pi\left[2^{2 j+1}\right]^{2^{s-2-2 j}} \\
\equiv & {\left[\left(c_{1}-c_{0}\right) \lambda+\left(c_{g}-c_{0}\right) \mu\right]^{2\left(2 s_{-1) / 3}\right.}\left[\left(c_{1}-c_{0}\right) \mu+\left(c_{g}-c_{0}\right) \lambda\right]^{\left(2^{s-1) / 3}\right.} } \\
& (\bmod q) .
\end{aligned}
$$

In both cases $\tau(\chi)^{2 s-1}$ has been shown to be an $r$ th power in $Q\left(\zeta_{r}\right) / \mathfrak{q}$. Since $r \nmid\left(2^{s}-1\right) / r, \tau(\chi)^{r}$ is an $r$ th power in $Q\left(\zeta_{r}\right) / \mathfrak{q}$, and applying (1) yields the theorem.

CoRollary. Assume $2^{r-1} \not \equiv 1\left(\bmod \quad r^{2}\right)$. If $c_{1} \equiv c_{2} \equiv \cdots \equiv c_{r-1}$ $(\bmod q)$, then $q$ is an $r$ th power residue $(\bmod p)$.

Proof. If $r>3$, apply Theorem 3. If $r=3, \tau(\chi)^{3} \equiv\left(c_{0}-c_{1}\right)^{3}$ $(\bmod q)$.

A computation by John Brillhart shows that 1093 and 3511 are the only primes $r$ less than $2^{24}$ for which $2^{r-1} \equiv 1\left(\bmod r^{2}\right)$. 


\section{BIBLIOGRAPHY}

1. Nesmith C. Ankeny, Criterion for $r$ th power residuacity, Pacific J. Math. 10 (1960), $1115-1124$.

2. H. Hasse, Vorlesungen über Zahlentheorie, $2^{\text {nd }}$ ed., Springer Verlag, Berlin 1964.

3. C. G. J. Jacobi, De Residuis Cubicis Commentatio Numerosa, Journal für die reine und angewandte Mathematik 2 (1827), 66-69.

4. Emma Lehmer, Artiads characterized, Journal of Mathematical Analysis and Applications 15 (1966), 118-131.

5. Joseph B. Muskat, Criteria for solvability of certain congruences, Canad. J. Math. 16 (1964), 343-352.

6. T. Pepin Memoire sur les lois de réciprocité relatives aux résidues de puissances, Pontificia accademia delle scienze, Atti 31 (1877), 40-148.

Received January 19, 1966. This research was sponsored in part by the National Science Foundation under Research Grant GP-2091. 


\section{PACIFIC JOURNAL OF MATHEMATICS}

\section{EDITORS}

\author{
H. SAMELSON \\ Stanford University \\ Stanford, California \\ J. P. JANS \\ University of Washington \\ Seattle, Washington 98105
}

\section{J. DugundJI}

University of Southern California Los Angeles, California 90007

RICHARD ARENS

University of California

Los Angeles, California 90024

\section{ASSOCIATE EDITORS}
E. F. BECKENBACH
B. H. NeumanN
F. WOLF
K. YOSIDA

\section{SUPPORTING INSTITUTIONS}

\author{
UNIVERSITY OF BRITISH COLUMBIA \\ CALIFORNIA INSTITUTE OF TECHNOLOGY \\ UNIVERSITY OF CALIFORNIA \\ MONTANA STATE UNIVERSITY \\ UNIVERSITY OF NEVADA \\ NEW MEXICO STATE UNIVERSITY \\ OREGON STATE UNIVERSITY \\ UNIVERSITY OF OREGON \\ OSAKA UNIVERSITY \\ UNIVERSITY OF SOUTHERN CALIFORNIA
}

\author{
STANFORD UNIVERSITY \\ UNIVERSITY OF TOKYO \\ UNIVERSITY OF UTAH \\ WASHINGTON STATE UNIVERSITY \\ UNIVERSITY OF WASHINGTON \\ AMERICAN MATHEMATICAL SOCIETY \\ CHEVRON RESEARCH CORPORATION \\ TRW SYSTEMS \\ NAVAL ORDNANCE TEST STATION
}

Mathematical papers intended for publication in the Pacific Journal of Mathematics should be typewritten (double spaced). The first paragraph or two must be capable of being used separately as a synopsis of the entire paper. It should not contain references to the bibliography. Manuscripts may be sent to any one of the four editors. All other communications to the editors should be addressed to the managing editor, Richard Arens at the University of California, Los Angeles, California 90024 .

50 reprints per author of each article are furnished free of charge; additional copies may be obtained at cost in multiples of 50 .

The Pacific Journal of Mathematics is published monthly. Effective with Volume 16 the price per volume (3 numbers) is $\$ 8.00$; single issues, $\$ 3.00$. Special price for current issues to individual faculty members of supporting institutions and to individual members of the American Mathematical Society: $\$ 4.00$ per volume; single issues $\$ 1.50$. Back numbers are available.

Subscriptions, orders for back numbers, and changes of address should be sent to Pacific Journal of Mathematics, 103 Highland Boulevard, Berkeley 8, California.

Printed at Kokusai Bunken Insatsusha (International Academic Printing Co., Ltd.), No. 6, 2-chome, Fujimi-cho, Chiyoda-ku, Tokyo, Japan.

PUBLISHED BY PACIFIC JOURNAL OF MATHEMATICS, A NON-PROFIT CORPORATION

The Supporting Institutions listed above contribute to the cost of publication of this Journal, but they are not owners or publishers and have no responsibility for its content or policies. 


\section{Pacific Journal of Mathematics \\ Vol. 20, No. $2 \quad$ October, 1967}

Edward Dewey Davis, Ideals of the principal class, $R$-sequences and a certain monoidal transformation ............................. 197

Richard Mansfield Dudley, Sub-stationary processes ................ 207

Newton Seymour Hawley and M. Schiffer, Riemann surfaces which are doubles of plane domains ......................... 217

Barry E. Johnson, Continuity of transformations which leave invariant certain translation invariant subspaces ................... 223

John Eldon Mack and Donald Glen Johnson, The Dedekind completion of

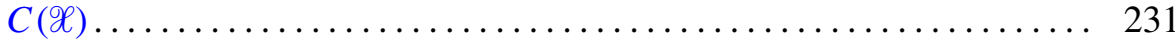

K. K. Mathur and R. B. Saxena, On the convergence of quasi-Hermite-Fejér interpolation................................... 245

H. D. Miller, Generalization of a theorem of Marcinkiewicz............ 261

Joseph Baruch Muskat, Reciprocity and Jacobi sums ............... 275

Stelios A. Negrepontis, On a theorem by Hoffman and Ramsay .......... 281

Paul Adrian Nickel, A note on principal functions and multiply-valent canonical mappings .............................. 283

Robert Charles Thompson, On a class of matrix equations ............. 289

David Morris Topping, Asymptoticity and semimodularity in projection lattices ........................................ 317

James Ramsey Webb, A Hellinger integral representation for bounded linear functionals

Joel John Westman, Locally trivial $C^{r}$ groupoids and their representations...

Hung-Hsi Wu, Holonomy groups of indefinite metrics 